\title{
Morphological and Quantitative Study of Neurons in the Gracile Nucleus of the Camel Brain Stem
}

\author{
Saleh M. Al-Hussain ${ }^{1 * \#}$, Raith A. Al-Saffar ${ }^{1}$, Sami I. Zaqout ${ }^{2 \#}$ \\ ${ }^{1}$ Anatomy Department, Faculty of Medicine, Jordan University of Science and Technology, Irbid, Jordan \\ ${ }^{2}$ Anatomy Department, Faculty of Medicine, Islamic University of Gaza, Gaza, Palestine \\ Email: "smbanihani@just.edu.jo
}

Received August 27, 2011; revised October 13, 2011; accepted November 3, 2011

\begin{abstract}
Neurons in the gracile nucleus of the camel brain stem were studied by Golgi method. Neurons were classified based on soma size and shape, density of dendritic tree, morphology and distribution of appendages. Six types of neurons were identified. Type I neurons had very large somata with appendages on their somata and distal dendrites. Type II neurons had large somata and almost smooth dendrites. Type III neurons displayed medium size somata with dendritic appendages of different forms. Type IV neurons were small to medium spheroidal or triangular neurons. Somata and dendrites of these neurons had appendages of different forms. Type $\mathrm{V}$ medium-size neurons had bipolar, round or fusiform somata and poorly branching dendritic tree. Some spines and appendages were seen on somata and dendrites of these neurons. Neurons of type VI were medium-size unipolar, round or fusiform with spines on their dendrites. The radiating branching pattern was more common than the tufted for all types of neurons. Wide overlap between widths of dendrites of different orders was found for all neuronal types. Hopefully, this study will improve our understanding of the role of the gracile nucleus as major center for sensory information processing and contribute to our understanding of comparative neuroanatomy and neurophysiology.
\end{abstract}

Keywords: Camel; Gracile; Neurons; Golgi

\section{Introduction}

The dorsal column nuclei (DCN) are among the most throughly studied structures in the mammalian central nervous system from the anatomical, physiological and behavioral point of view [1]. The DCN (gracile and cuneate nuclei) are sensory nuclei which are interposed in the ascending somesthetic pathway from the periphery to the somatosensory thalamus [2]. Nerve fibers from receptors mediating proprioception, kinesthesia, stereognosis and vibration enter directly into the dorsal columns of the spinal cord and ascend ipsilaterally, without synapsing, to the gracile $(\mathrm{Gr})$ and cuneate $(\mathrm{Cu})$ nuclei. The fibers from the leg (hindlimb) ascend in the more medial portion of the dorsal column in the fasciculus gracilis, while those fibers from the upper extremity (forelimb) ascend in the more lateral fasciculus cuneatus [3].

In mammals, hindlimb and forelimb afferents nerve fibers project to separate bulbar targets, namely the le Gr and $\mathrm{Cu}$ nuclei. This organization allows assay of interacttions between distinct components of the somatosensory system during the course of development [4]. There is a

\footnotetext{
"Corresponding author.

\#These authors contributed equally to this work.
}

steady increase in size of the dorsal fasciculi and their bulbar nuclei throughout the phylogenetic scale from lower animals to man [5]. The two nuclei make their first definite appearance in reptiles and reach their highest stage of development in mammals [6]. It is believed that the development of the dorsal fasciculi and their nuclei in the mammalian and primate series is correlated with increasing sensory discrimination in the skin and the increased development of proprioceptive sense in the limb [5].

The concept that the DCN function only as relay stations [7] is too simplistic in view of accumulated evidence that the synaptic passage of sensory information is capable of considerable modulation. Now it is known that the DCN are major integrating centers in which the processes of presynaptic and postsynaptic inhibition and facilitation regulate rostral transmission of afferent information [8-11].

Camel has adapted to live in desert in several ways. It has long, strong legs. Powerful muscles in the upper part of the legs allow the animal to carry heavy loads for long distances. When walking, the camel moves both feet on one side of its body, then both feet on the other. This gait suggests the rolling motion of a boat, explaining the 
camel's "ship of the desert" nickname [12]. Camel has two toes on each foot. A hoof that looks like a toenail grows at the front of each toe. Cow, horse, and many other animals walk on their hoofs. But the camel walks on a broad pad that connects its two long toes. This cushion-like pad spreads when the camel places its foot on the ground. The pad supports the animal on loose sand. The camel's cushioned feet make almost no sound when the animal walks or runs [13]. These features of the limbs of the camel enable it to walk over the softest kinds of sand that are difficult for any other animal to move on them. To the best of our knowledge, the Gr of the camel had not been studied before. Hopefully, this study will find special features for neurons in the Gr nucleus of the camel.that represent the second order neurons of pathways of fine touch, pressure, vibration and proprioception from the leg (hindlimb).

The aims of this study were to: 1) Identify the different neuronal types in the Gr of the camel and describe their morphological features; 2) Study certain quantitative features of these neurons such as mean diameter of cell body and dendrites of different orders and types of dendritic branching patterns and 3) Compare neurons in the camel's Gr with their counterparts in other species.

\section{Materials and Methods}

This study focus on studying different neuronal types in the gracile nucleus of the camel using Golgi method. Ten camels' brain stems obtained from slaughtered camels and fixed in $10 \%$ formalin for months. Two modifications of Golgi-Kopsch method [14,15] were carried out in this study. Interesting and well impregnated neurons were studied (drawn, measured and photographed) by using Nikon light microscope equipped with camera lucida, oculometer and photographing system. Mean diameter of cell body and diameter of primary, secondary and tertiary dendrites were measured. Finally, dendritic branching patterns: radiating (dendrites that give two branches) and tufted (dendrites that give more than two branches) of different neuronal types were studied.

\section{Results}

The Gr of the camel brain stem extends from the lower limit of pyramidal decussation; $5 \mathrm{~mm}$ below the obex; up to $1 \mathrm{~mm}$ above the obex (Figure 1). The areas occupied by $\mathrm{Gr}$ were studied and delineated using hematoxylin and eosin preparations. To characterize further morphological and quantitative features of neurons of this nucleus, blocks of the medulla at the level of the Gr were impregnated by Golgi technique.

\subsection{Morphological Study}

The neurons in Gr were classified according to: 1) soma size and shape; 2) density of dendritic tree and 3) presence or absence of different types of spines and/or appendages on dendrites and/or cell bodies.

Type I Neurons: These multipolar or elongated neurons (Figure 2) represented the largest impregnated neuronal type in the Gr. They had very large somata with mean diameters range from 52.5 to $74 \mu \mathrm{m}(\mathrm{MD}=61.53$ $\mu \mathrm{m} \pm 5.844, \mathrm{n}=19$ ). Somatic spines were seen for some neurons of this type. Four to seven primary dendrites emerged from the cell body of these neurons. These dendrites showed moderate arborizations.. Appendages were detectable all along the dendritic processes of this neuronal type although they became more prominent progressively on the distal dendrites. These appendages included mainly small rounded-like protrusions and slender stalks with or without spheroidal endings. Regarding the axons, only initial axonal segments of these neurons were impregnated in this study.

Type II Neurons: These multipolar or elongated neurons represented the most frequently impregnated neuronal type in the Gr (Figure 3). They had large somata with mean diameters range from 25.5 to $42.5 \mu \mathrm{m}$ (MD = $31.65 \mu \mathrm{m} \pm 4.31, \mathrm{n}=51$ ). There were no detectable somatic spines for these neurons. These neurons emitted two to six dendrites. They were generally smooth with only few spines found for distal dendrites. Only initial axonal segments of these neurons were impregnated.

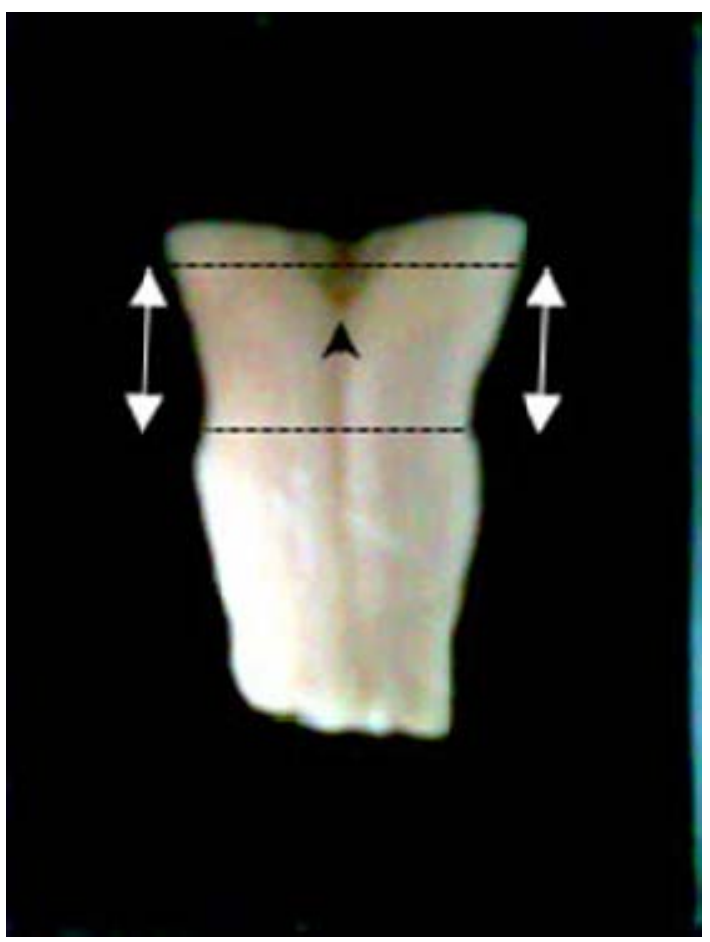

Figure 1. Dorsal view photograph of camel's brain stem to demonstrate the area occupied by $\mathrm{Gr}$ in the medulla (between the two dotted lines). The arrowhead indicates to the obex of the medulla. 


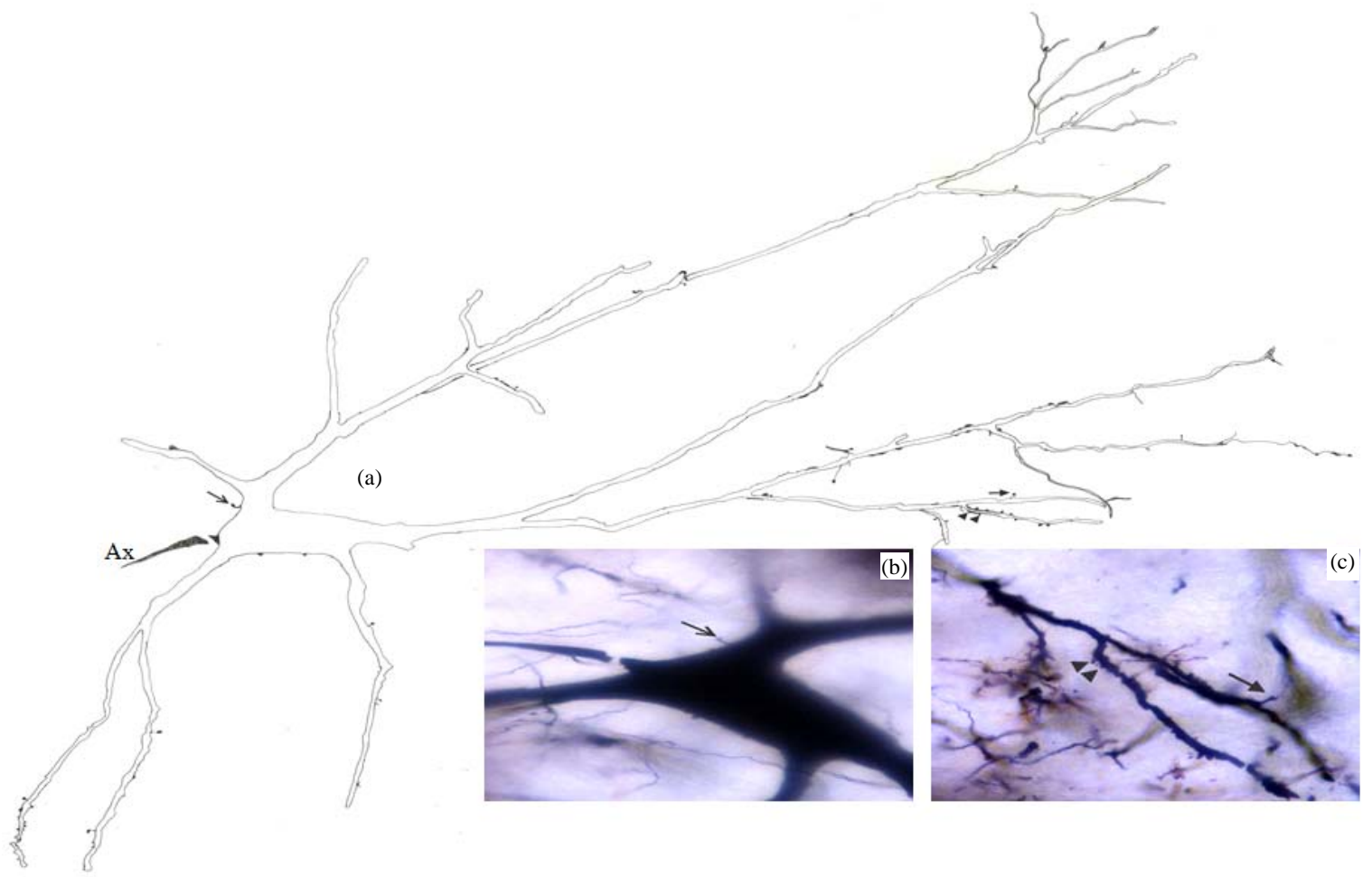

Figure 2. Camera lucida drawing (a) of type I neuron. The arrow indicates to somatic spine which is also shown in photomicrograph (b); Dendritic spine and protrusions are indicated by the arrow and arrowheads respectively in both (a) and photomicrograph $(\mathrm{c}) ; \times$ for drawing $=\mathbf{2 2 0}$.

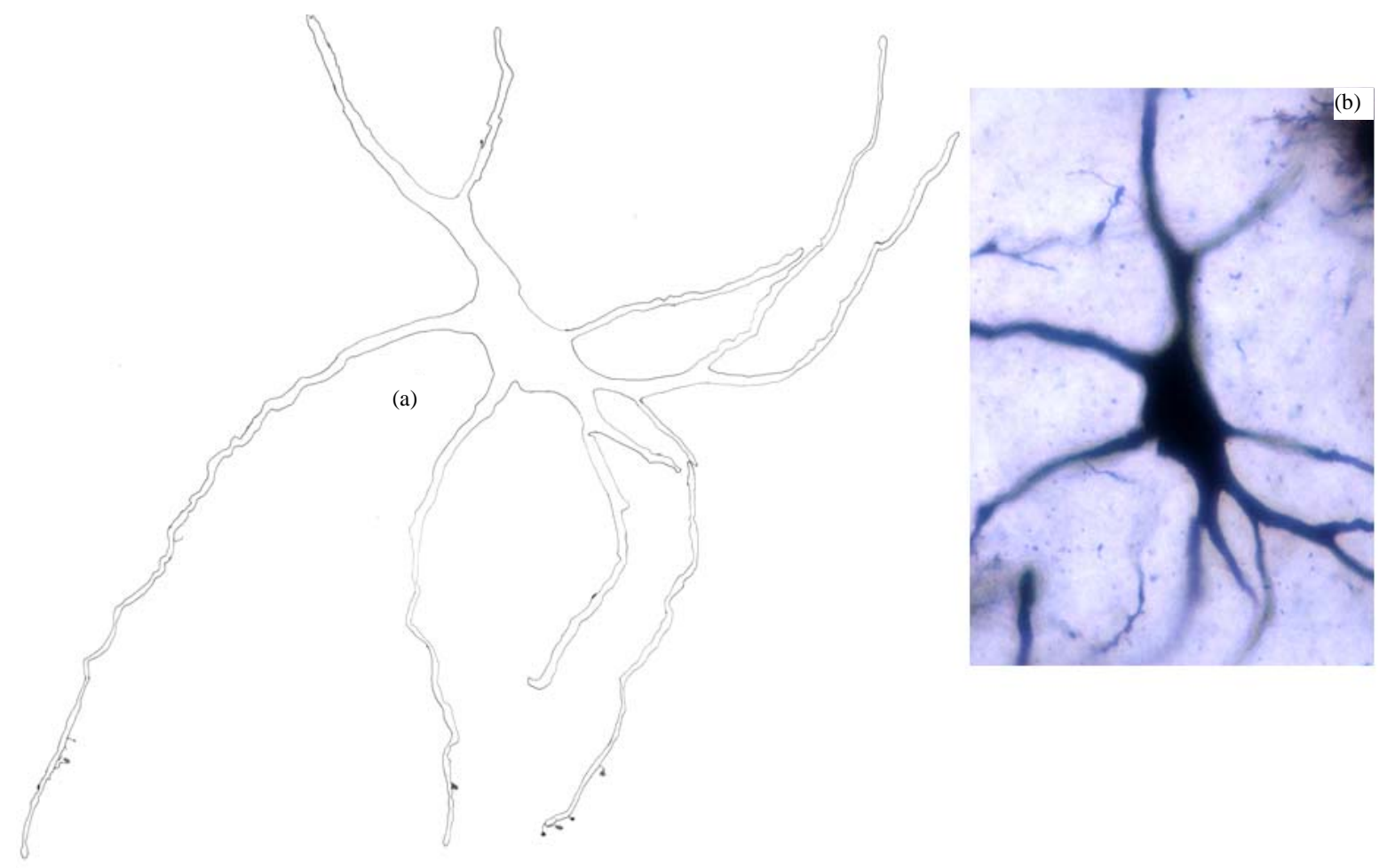

Figure 3. Camera lucida drawing (a) and photomicrograph (b) of type II neuron. Note that the dendrites are almost smooth. $\times$ for drawing $=\mathbf{4 5 0}$. 
Type III Neurons: These medium-sized neurons displayed ovoid, elongated, triangular or multipolar somata (Figures 4 and 5). Few of these neurons also exhibited pyramidal-like shape. Their somata mean diameters range from 15 to $25 \mu \mathrm{m}(\mathrm{MD}=20.70 \mu \mathrm{m} \pm 3.531, \mathrm{n}=28)$. Somatic spines were rarely found for neurons of this type.
Three to six primary dendrites emerged from the cell body and sparsely ramified. Appendages of different forms were detectable all along some dendritic processes. Thin long side branches with spines were detected for neurons of this type (Figure 5). Only initial axonal segments of these neurons were impregnated.

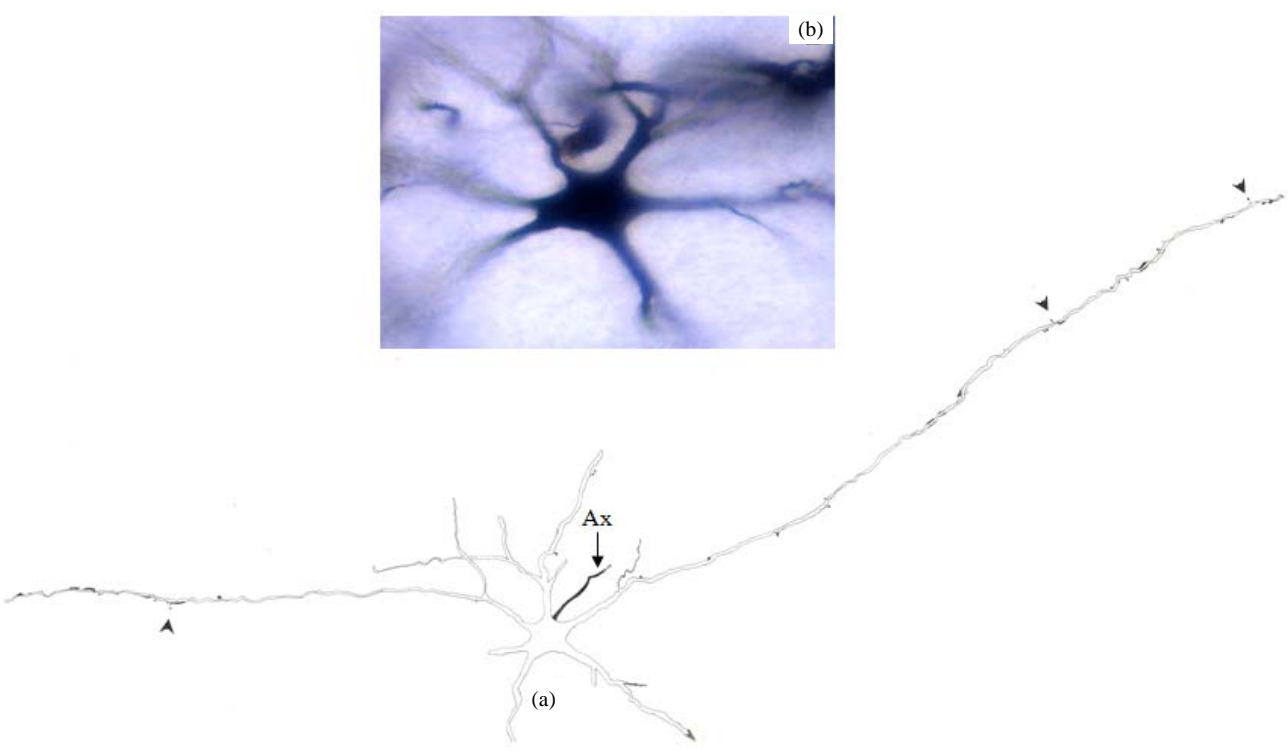

Figure 4. Camera lucida drawing (a) and photomicrograph (b) of type III neuron. Note the paucity of dendritic appendages (arrowheads). Ax $=$ Axon. $\times$ for drawing $=300$.

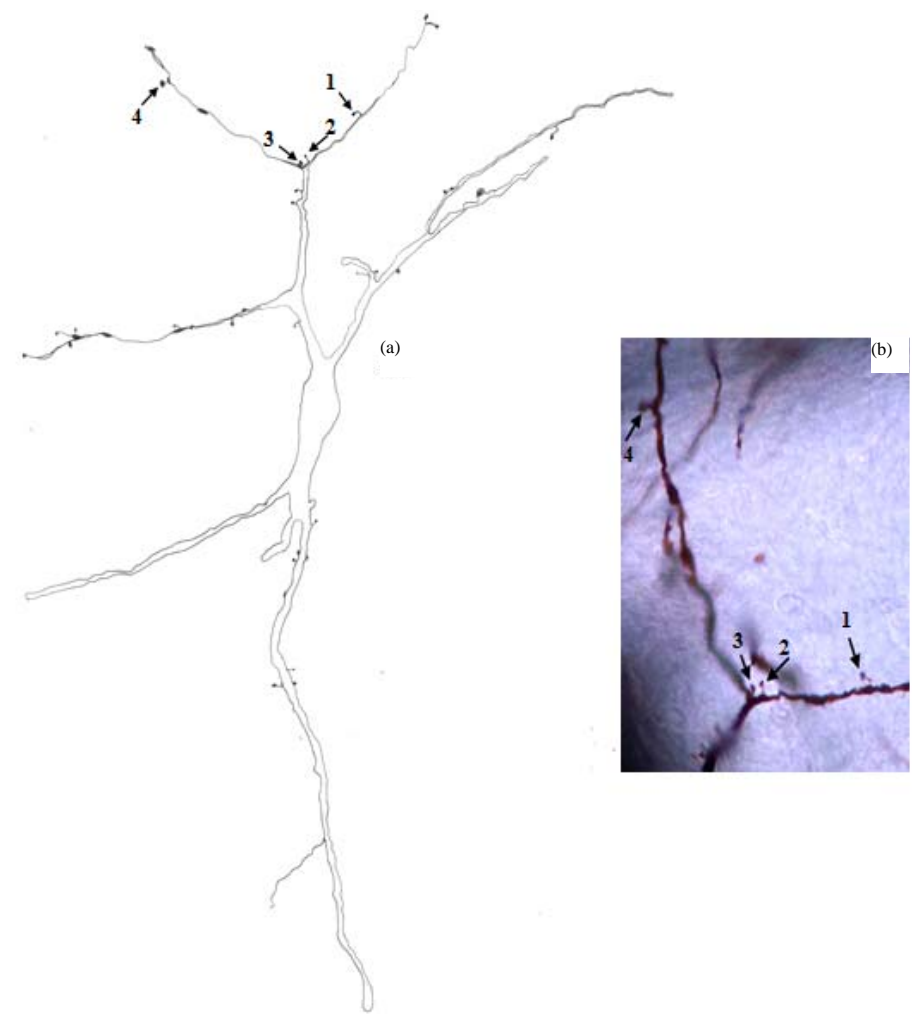

Figure 5. Camera lucida drawing (a) of type III neuron. The numbered arrows indicate to four dendritic appendages of different shapes which are also shown in photomicrograph (b). $\times$ for drawing $=400$. 
Type IV Neurons: These were small to medium spheroidal or triangulated neurons (Figures 6 and 7). Somatic spines and grape-like appendages were seen for these neurons. The neurons of this type were subdivided into two subtypes according to the density of their dendritic trees. Type IVa (Figure 6) consisted of neurons with somata diameters range from 12 to $21 \mu \mathrm{m}(\mathrm{MD}=17.58$ $\mu \mathrm{m} \pm 2.499, \mathrm{n}=18$ ). They had two to four primary dendrites with little or no dendritic branching. Type IVb (Figure 7) consisted of neurons with somata diameters range from 10.5 to $22 \mu \mathrm{m}(\mathrm{MD}=17.19 \mu \mathrm{m} \pm 2.938, \mathrm{n}=$ 29). They had three to four primary dendrites and their ramification as a whole was generally more extensive as compared with type IVa. The dendrites of type IV neurons had spines and appendages all along their courses. Thin side branches of different lengths with or without spines were commonly observed for the dendrites of these neurons (Figures 6 and 7). Axons were observed originating from a distinct axon hillock and coursing a short distance. Some of these axons showed spines on their initial segments. No axon collaterals were observed.

Type V Neurons: These bipolar, round or fusiform neurons (Figure 8) had medium somata with mean diameters range from 16 to $23.5 \mu \mathrm{m}(\mathrm{MD}=19.72 \mu \mathrm{m} \pm$ $2.353, n=18$ ). Somatic appendages were seen for some neurons of this type. They had two dendrites that ran in opposite directions with little or no branching. Dendrites of these neurons displayed some spines. Thin long side branches with spines were sometimes observed on dendrites of these neurons. Only initial axonal segments of these neurons were impregnated and arose from cell body or primary dendrite.

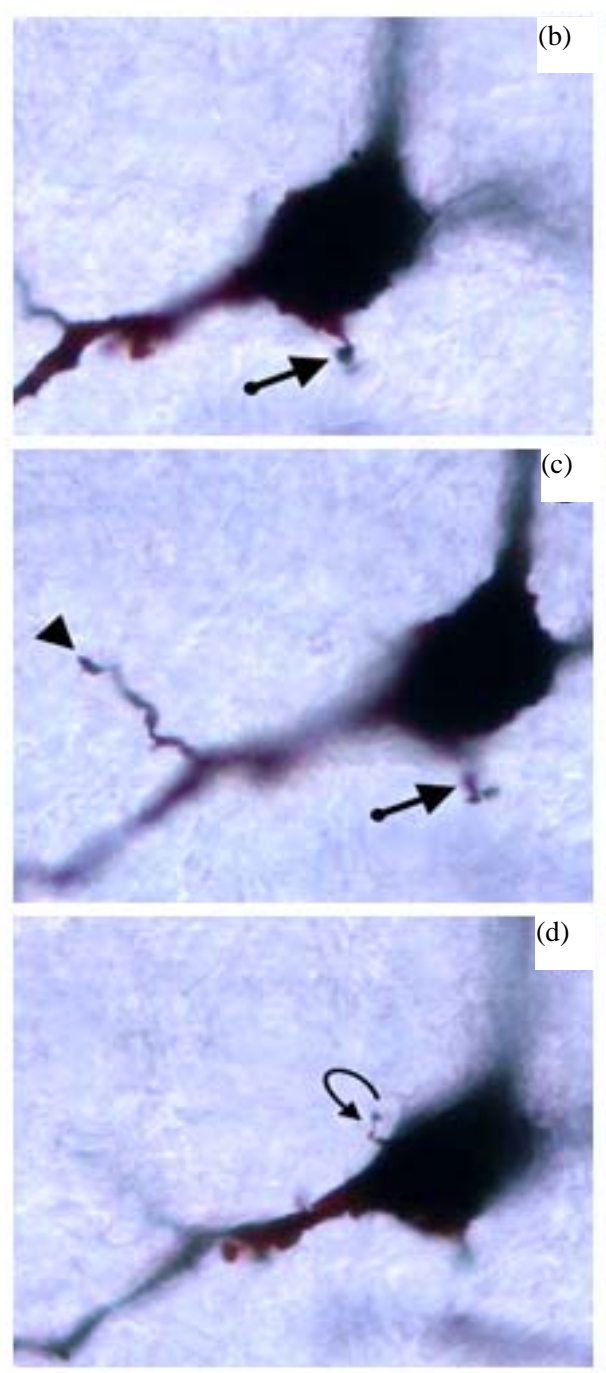

Figure 6. Camera lucida drawing (a) of type IVa neuron. Note the poor dendritic tree. The arrow indicates to somatic grape-like appendage which is also shown in photomicrographs (b) and (c). The curved arrow points to somatic spine which is also shown in photomicrograph (d). Thin side branch indicated by arrowhead is also shown in photomicrograph (c). Other thin side branches are indicated by stars. $A x=$ Axon. $\times$ for drawing $=470$. 


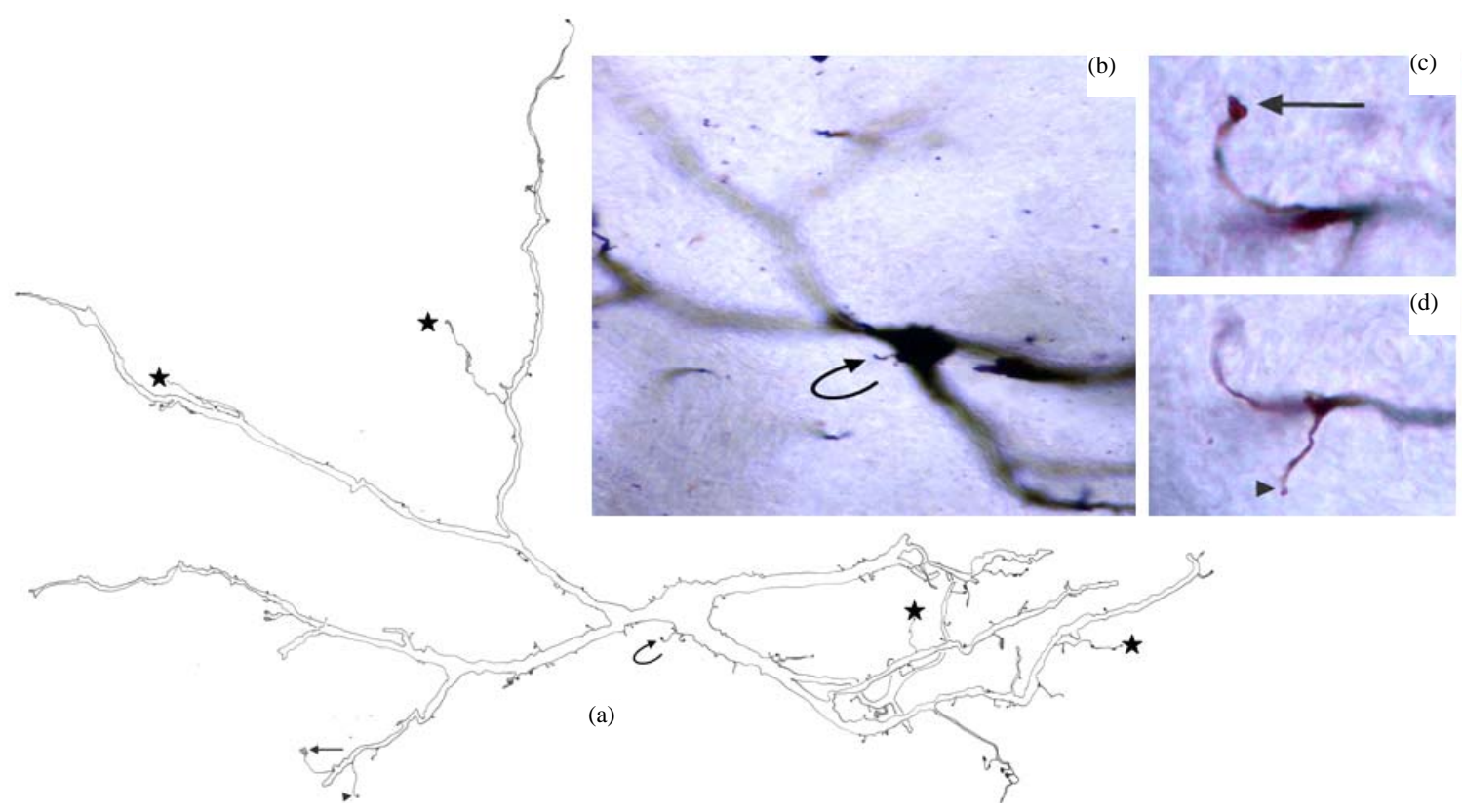

Figure 7. Camera lucida drawing (a) of type IVb. Note that the dendritic ramification as a whole is generally more extensive as compared with type IVa. The curved arrow indicates to somatic spine which is also shown in photomicrograph (b); The arrow and arrowhead indicate to two thin side branches which are also shown in photomicrographs (c) and (d) respectively. Other thin side branches are indicated by stars. $\times$ for drawing $=\mathbf{5 0 0}$.
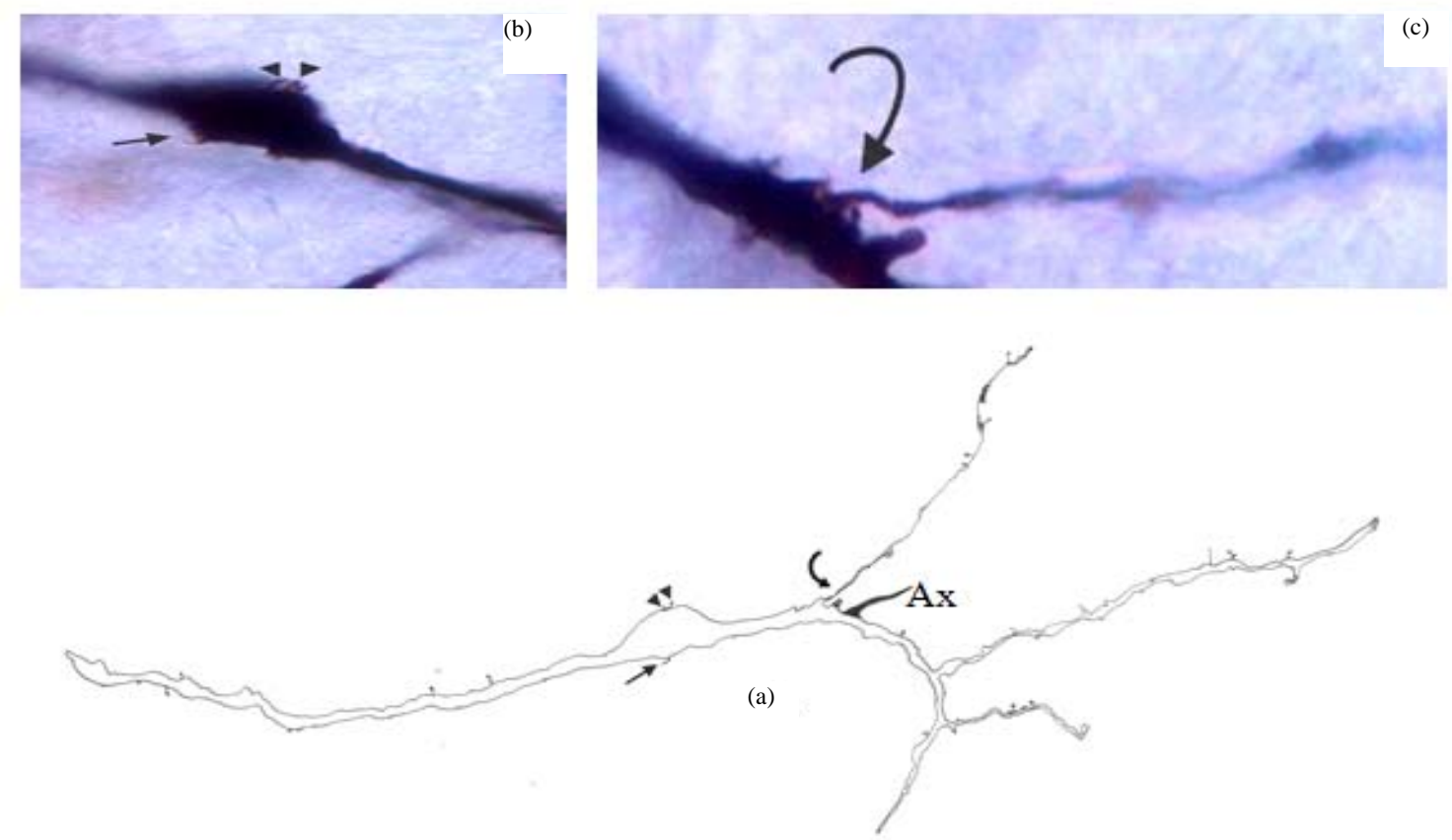

Figure 8. Camera lucida drawing (a) of type V neuron. Somatic hair-like appendage and two protrusions indicated by arrow and two arrowheads respectively are also shown in photomicrograph (b); Note the thin long side branch (curved arrow) which is also shown in photomicrograph (c). Ax = Axon. $\times$ for drawing $=415$.

Type VI Neurons: These neurons (Figure 9) represented the least frequently impregnated neuronal type in the Gr. They displayed unipolar, round or fusiform neurons. They had medium somata with mean diameters range from 16.5 to $18 \mu \mathrm{m}(\mathrm{MD}=17.60 \mu \mathrm{m} \pm 0.652, \mathrm{n}=4)$.
There were no detectable somatic spines for these neurons. There was little or no dendritic branching. Dendrites of these neurons displayed some spines and protrusions. Thin side branches were seen for some neurons of this type. Only the initial axonal segments of these neu- 
rons were impregnated and arose from the primary or secondary dendrites.

\subsection{Quantitative Study}

Neurons in Gr were studied quantitatively. The mean diameters of cell bodies of these neurons were already included in the first part of this study. The other parameters studied in this part were: 1) type of dendritic branching pattern: tufted (give more than two branches) or radiating (give two branches) and 2) diameter of primary, seconddary and tertiary dendrites.

The neuronal types I, II, III, IV and V were studied quantitatively (Table 1 and Figure 10). Type VI neurons were excluded because the number of their impreg- nated dendrites was insufficient for quantitative analysis.

Type I Neurons: The branching pattern analysis revealed that the vast majority of the primary, secondary and all of the tertiary dendrites had a radiating branching pattern (Table 1). The quantitative measurements of widths of dendrites of different order showed a very wide range of variability of widths of dendrites of different orders as well as of the same order (Figure 10). The diameters of the first order dendrites range from 2 to $22 \mu \mathrm{m}$, the diameters of the second order dendrites range from 1 to $13 \mu \mathrm{m}$ and the diameters of the third order dendrites range from 1 to $10 \mu \mathrm{m}$. Overlap of diameters was found not only between primary and secondary dendrites, but also between primary and tertiary dendrites (Figure 10).

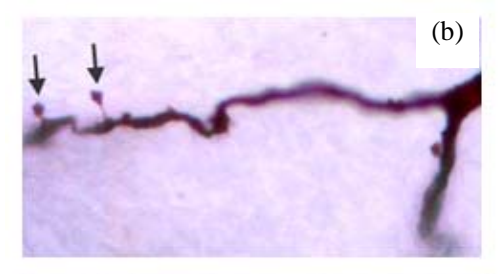

(b)

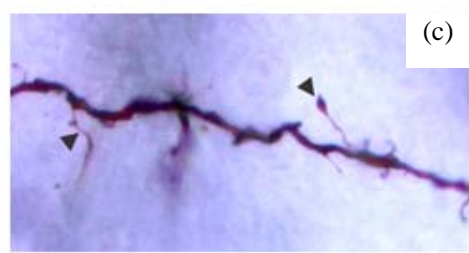

(c)

(a)

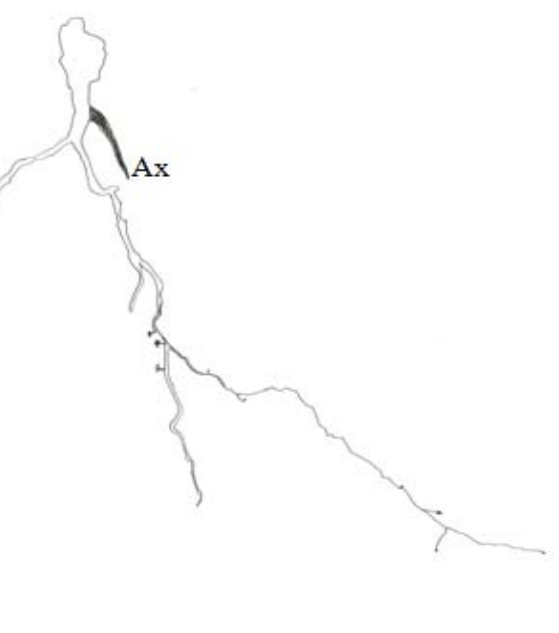

Figure 9. Camera lucida drawing (a) of type VI neuron. The arrows indicate to two dendritic spines which are also shown in photomicrograph (b). Two thin side branches indicated by arrowheads are also indicated by arrowheads in photomicrograph (c). Ax = Axon. $\times$ for drawing $=485$.

Table 1. Branching characteristics of dendrites of different neuronal types in the Gr.

\begin{tabular}{|c|c|c|c|c|c|c|c|c|c|}
\hline \multirow[b]{2}{*}{ Neuronal type } & \multicolumn{3}{|c|}{ Primary } & \multicolumn{3}{|c|}{ Secondary } & \multicolumn{3}{|c|}{ Tertiary } \\
\hline & $\mathbf{R}$ & $\mathbf{T}$ & R:T & $\mathbf{R}$ & $\mathbf{T}$ & R:T & $\mathbf{R}$ & $\mathbf{T}$ & R:T \\
\hline $\begin{array}{l}\text { Gr Type I } \\
\mathrm{N}=19 \text { cells }\end{array}$ & 41 & 4 & 10.3 & 27 & 2 & 13.5 & 15 & 0 & - \\
\hline $\begin{array}{l}\text { Gr Type II } \\
\text { N=51 cells }\end{array}$ & 143 & 15 & 9.5 & 113 & 7 & 16.1 & 48 & 0 & - \\
\hline $\begin{array}{l}\text { Gr Type III } \\
\text { N=28 cells }\end{array}$ & 75 & 9 & 8.3 & 84 & 3 & 28 & 30 & 0 & - \\
\hline $\begin{array}{l}\text { Gr Type IV } \\
\mathrm{N}=47 \text { cells }\end{array}$ & 89 & 3 & 29.7 & 64 & 2 & 32 & 26 & 0 & - \\
\hline $\begin{array}{l}\text { Gr Type V } \\
\text { N=18 cells }\end{array}$ & 30 & 4 & 7.5 & 27 & 0 & - & 15 & 0 & - \\
\hline
\end{tabular}


Type I Neurons
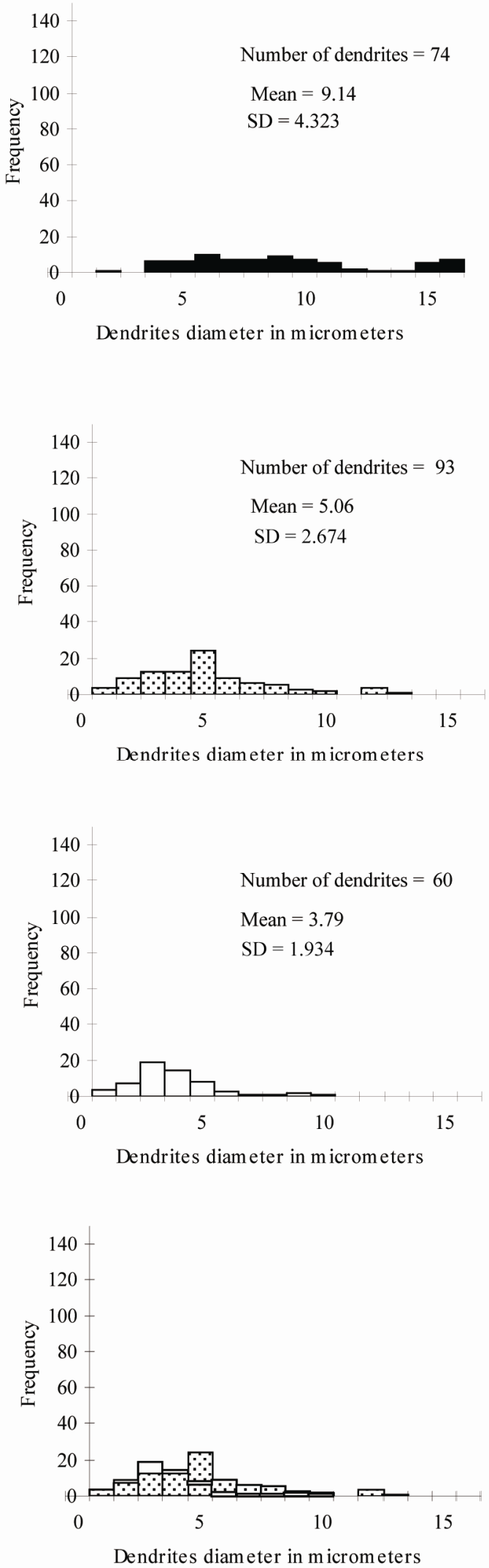

Type II Neurons
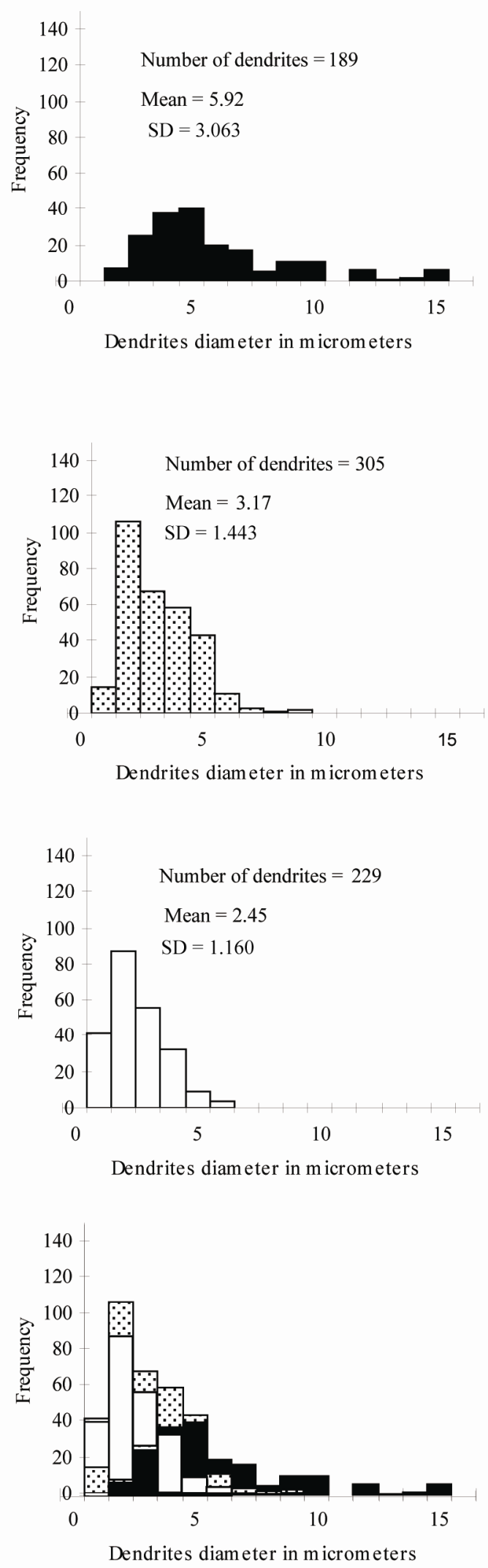
Type III Neurons
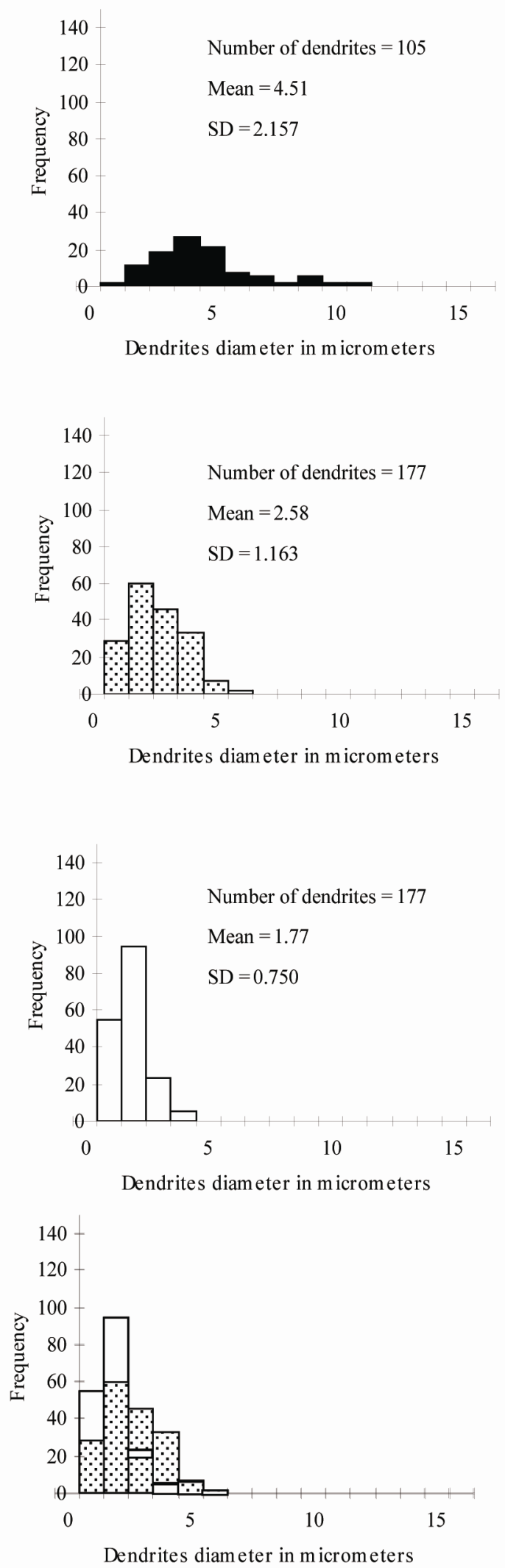

Type IV Neurons
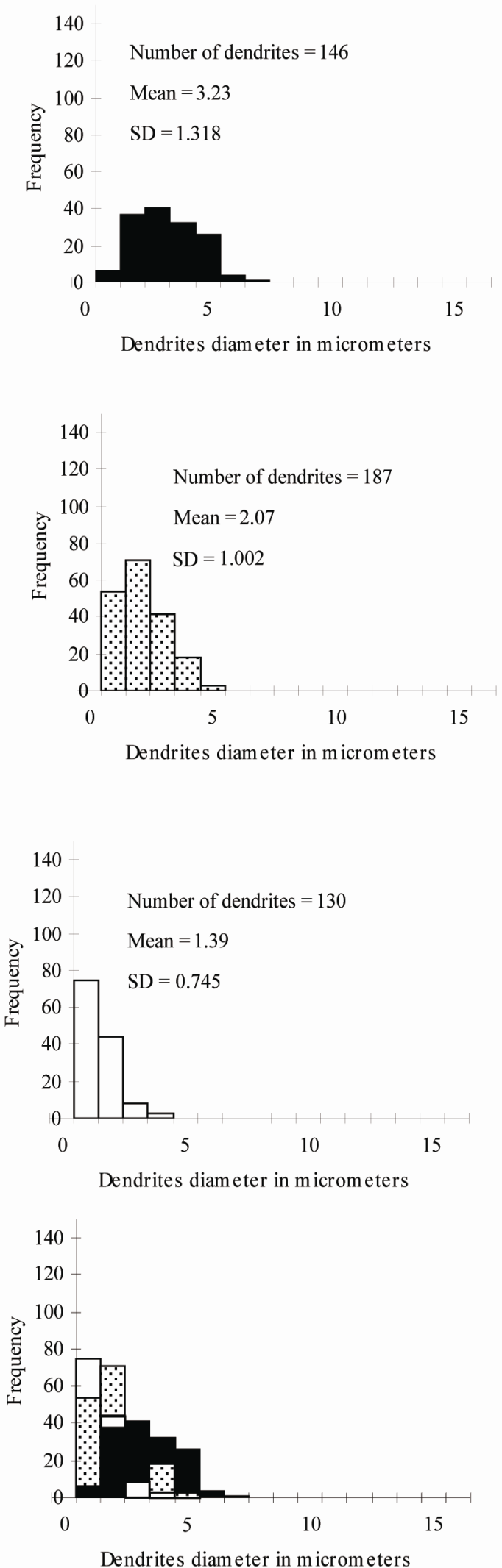
Type V Neurons
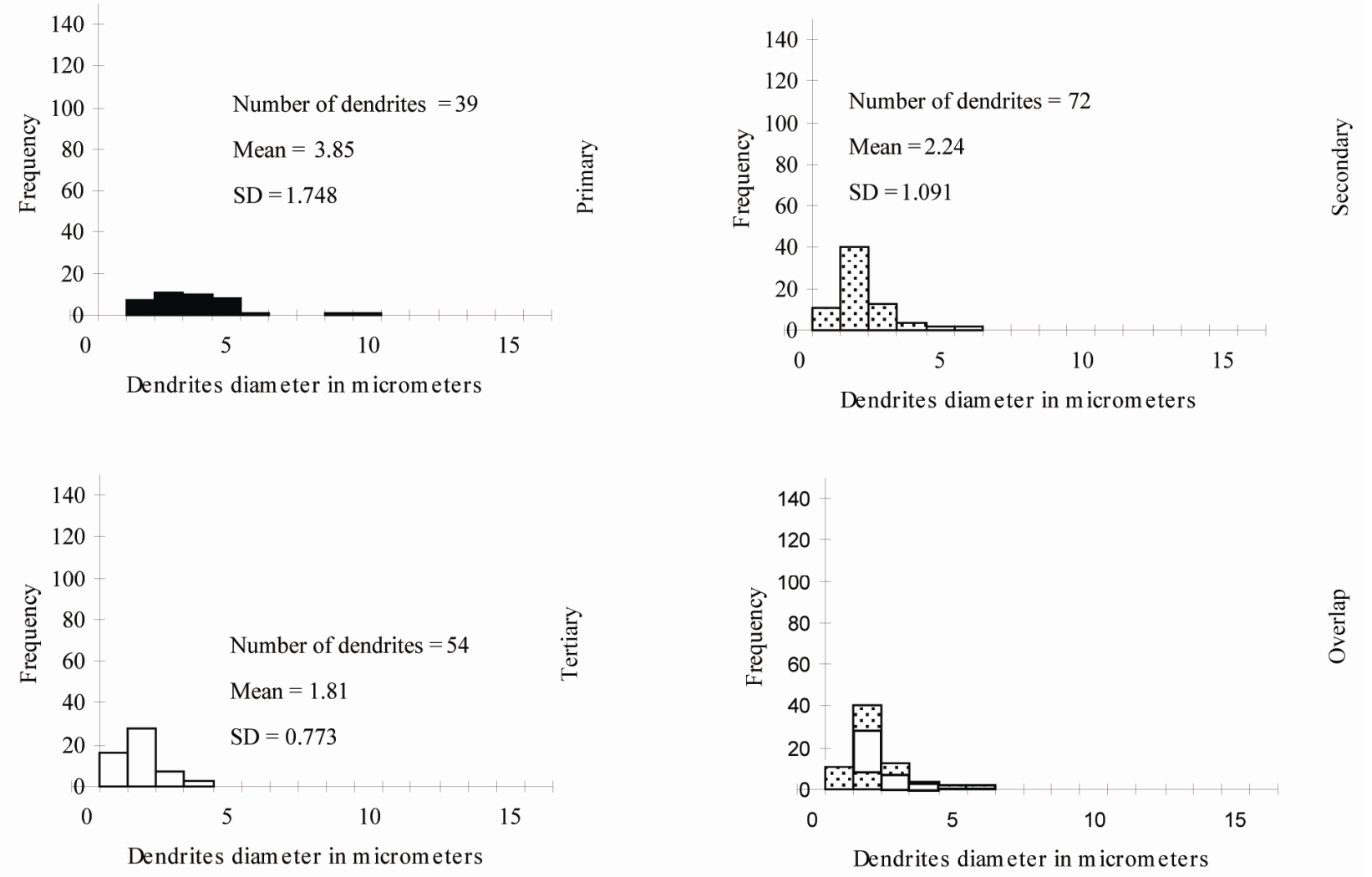

Figure 10. Percentage distribution histograms of the diameters of different order dendrites in Gr. In each column, from top to bottom, are histograms of primary dendrites, secondary dendrites and tertiary dendrites. The bottom row demonstrates the overlap between the diameters of the three order dendrites.

Type II Neurons: The branching pattern of the primary dendrites in this type exhibited both radiating and tufted branching patterns (Table 1). The radiating branching pattern was more common than tufted one. The vast majority of the secondary dendrites and all of the tertiary dendrites had a radiating branching pattern. Wide range of variability of widths of dendrites of different order as well as of the same order was existed. The diameters of the first order dendrites range from 2 to 15 $\mu \mathrm{m}$, the diameters of the second order dendrites range from 1 to $9 \mu \mathrm{m}$ and the diameters of the third order dendrites range from 0.5 to $6 \mu \mathrm{m}$. Overlap of diameters of different order neurons was clearly seen in this type (Figure 10).

Type III Neurons: The branching pattern of the primary dendrites in this type exhibited both radiating and tufted branching patterns (Table 1). The radiating branching pattern was more common than tufted one. The vast majority of the secondary dendrites and all of the tertiary dendrites had a radiating branching pattern. The diameters of the first order dendrites range from 1 - 11 $\mu \mathrm{m}$, the diameters of the second order dendrites range from 0.5 - $6 \mu \mathrm{m}$ and the diameters of the third order den- drites range from $0.5-4 \mu \mathrm{m}$. Overlap of diameters was found between primary, secondary and tertiary dendrites (Figure 10).

Type IV Neurons: The vast majority of the primary, secondary and all of the tertiary dendrites had a radiating branching pattern (Table 1). The variability of widths of dendrites of different order as well as of the same order was also existed in this type but within narrower range compared with previous described types (Figure 10). The diameters of the first order dendrites range from 1 to $7 \mu \mathrm{m}$, the diameters of the second order dendrites range from 0.5 to $5 \mu \mathrm{m}$ and the diameters of the third order dendrites range from 0.5 to $4 \mu \mathrm{m}$ Overlap of diameters was found between primary, secondary and tertiary dendrites (Figure 10).

Type V Neurons: The vast majority of the primary, secondary and all of the tertiary dendrites had a radiating branching pattern (Table 1). The diameters of the first order dendrites range from $1.5-10 \mu \mathrm{m}$, the diameters of the second order dendrites range from $1-6 \mu \mathrm{m}$ and the diameters of the third order dendrites range from 0.5 - 4 $\mu \mathrm{m}$. Overlap of diameters was also found between primary, secondary and tertiary dendrites (Figure 10). 


\section{Discussion}

The dorsal fasciculi of the spinal cord are the chief pathways for the conduction of proprioception (sense of position and movements) and tactile discrimination which reach the thalamus and ultimately the cortex after a relay at a bulbar level; the $\mathrm{Gr}$ and $\mathrm{Cu}$. These nuclei were particularly attractive targets for studying early stages of sensory processing in the somatosensory pathways [16]. In all species studied, these nuclei receive somatotopically arranged primary afferent fibers, contain a representational map of the trunk and limbs, and give rise to the medial lemniscus, the fiber system that provides the fastest and more precisely organized somatosensory input to the thalamus [17-24].

To the best of our knowledge, this investigation was the first morphological and quantitative study done on the camel Gr using Golgi impregnation techniques. The $\mathrm{Gr}$ in other species have been studied using different techniques such as Nissl stain, Golgi impregnation, HRP, EM and immunocytochemistry. These studies provided different information about neurons in the Gr. However, several aspects of cell morphology remained unclear and limited. Most of the previous morphological studies of the Gr classified neurons according to soma size and shape. The Golgi method still the most suitable tool to study the morphological and quantitative features of neurons that mediate their functional activities. A through description of morphological features of neurons in the Gr of the camel may shed some light on the role of this nucleus and contribute to our understanding of comparative neuroanatomy. The present findings in camel confirm and extend previous observations in other studied mammalian species (rat, cat) on the presence of heterogeneous population of neuronal types in the Gr [25-28]. Both similarities and differences were found between neurons in the Gr of the camel and their counterparts in the rat and cat.

The very large type I neurons with somata mean diameter about $60 \mu \mathrm{m}$ found in the camel in this study was not reported in any previous study in the Gr For example, the largest neuronal type found in the rat have mean diameter about $25 \mu$ [25]. Type II neurons in the camel were comparable to large neurons found in the rat [25]. These neurons of the two species have smooth dendritic trees and comparable size. Some of type III neurons in this study have pyramidal-like shape and this made them similar to pyramidal neurons described in the rat [25]. The small cells of type IVa found in the camel were similar to small cells described in the rat [25]. In both species, these cells have poorly branching dendritic trees where dendrites divided only once or twice. Type IVb neurons in the camel were found to be similar to spherecal medium-sized neurons found throughout the $\mathrm{Gr}$ in the rat [25]. These neurons of the two species were compa- rable regarding to their soma shape, size, number of primary dendrites and forms and distribution of dendritic appendages. They were small to medium spheroidal or triangulated neurons. They have three to four dendrites with spines and appendages along their courses. Interneurons in many areas of the central nervous system have been described as having small somata, infrequently branching dendrites, dendritic appendages of different forms and locally branching axons [29]. This suggest that the type IV neurons in the camel and the small and medium neurons in the rat [25] were most probably interneurons. In the cat, similar neurons were found whose axons ramify locally and therefore, were classified as interneurons [30]. It is important to mention that, no somatic spines or thin dendritic side branches were reported for those neurons in the rat and cat $[25,30]$. Somatic spines and thin side dendritic branches were commonly found for the type IV in the camel in this study. This made the type IV in the camel more complex than their counterparts in the rat and cat. Type $\mathrm{V}$ neurons in the camel were similar to fusiform neurons found in the rat [25] and cat [31]. These neurons in the three species have two dendrites that ran in opposite directions with little or no branching. A combination of HRP and Golgi observations in the cat [31] suggested that these neurons were interneurons. Again, thin long side branches with spines were observed on the dendrites of these neurons in the camel but not in the rat or cat. Unipolar cells described in the rat [25] differ slightly from type VI neurons in the camel. In the rat, the dendrites of these cells were smooth while spines, protrusions and thin side branches were displayed for dendrites of this type in the camel.

Somatic spines and appendages found for some neuronal types in the Gr of the camel in this study were not reported in previous Golgi or HRP studies of the $\mathrm{Gr}$ in other species. Furthermore, at EM level [2,32] the major component of the synaptic population of the Gr in the cat and snake was formed mainly by boutons on dendrites. The results of this study on the other hand, may indicate that, in the Gr. of the camel, both axo-dendritic as well as axo-somatic contacts might be expected.

\section{Quantitative Analysis}

This quantitative study was the first to be done for neurons in the Gr. It is important to know the frequency and distribution of the radiating and tufted branching patterns along the dendritic trees. These two branching patterns affect the nerve impulse transmission in different ways [33]. The branching pattern analysis for all types of neurons in the $\mathrm{Gr}$ revealed that the radiating pattern was more common than the tufted one in primary, secondary and tertiary dendrites. Another interesting result from this study related to the wide overlap between widths of primary, secondary and tertiary dendrites of several neu- 
ronal types in the Gr. For instance, some of primary dendrites had smaller widths than secondary or even tertiary branches. This finding indicates that at EM level, only the very large and very small dendrites (the dendrites outside the overlap range) can be identified as first order and third order dendrites respectively.

\section{Conclusion}

The present data indicate to very complex information processing that take place in the camel Gr. This was supported by the presence of a wide variety of neurons comprising a broad spectrum of somatic size and shape, dendritic density, dendritic branching pattern, somatic spines and appendages and dendritic spines, appendages and side branches. The presence of the very large type I neurons and the somatic spines and appendages in this study may suggest that, neurons in the camel Gr could have more complex synaptic relationships and more complex information processing comparing to their counterparts in other species. Whether there is relationship between the special characteristic camel's limbs and the diversity of the Gr neurons and their spines, appendages and side branches is difficult to determine in this morphological study. Furthermore, this study may provide a background for future EM, electrophysiological and immunocytochemistry studies to clarify the exact role of the gracile nucleus.

\section{Acknowledgements}

This research was funded by research deanship at Jordan University of Science and Technology, Irbid, Jordan.

\section{REFERENCES}

[1] A. C. Norton, "The Dorsal Column System of the Spinal Cord. An Updated Review,” U.C.L.A., Brain Information Service, Los Angeles, 1969.

[2] C. K. Tan and P. Gopalakrishnakone, "The Fine Structure of the Dorsal Column Nucleus and the Nucleus of Bischoff of the Python (Python reticulatus)," Journal of Morphology, Vol. 190, No. 3, 1986, pp. 243-257. doi:10.1002/jmor.1051900302

[3] J. E. Mendoza and A. L. Foundas, "Clinical Neuroanatomy: A Neurobehavioral Approach,” Springer, Berlin, 2008, p. 33.

[4] R. W. Rhoades, J. T. Wall, N. L. Chiaia, C. A. BennettClarke and H. P. Killackey, "Anatomical and Functional Changes in the Organization of the Cuneate Nucleus of Adult Rats after Fetal Forelimb Amputation,” The Journal of Neuroscience, Vol. 13, No. 3, 1993, pp. 1106-1119.

[5] H. T. Chang and T. C. Ruch, "Organization of the Dorsal Columns of the Spinal Cord and Their Nuclei in the Spider Monkey,” Journal of Anatomy, Vol. 81, No. 2, 1947, pp. 140-149.

[6] C. U. Ariens-Kappers, G. C. Huber and E. C. Crosby, "The
Comparative Anatomy of the Nervous System of Vertebrates, Including Man,” Macmillan, New York, 1936.

[7] P. O. Therman, "Transmission of Impulses through the Burdach Nucleus,” Journal of Neurophysiology, Vol. 4, No. 2, 1941, pp. 153-166.

[8] G. Gordon and C. H. Paine, "Functional Organization in Nucleus Gracilis of the Cat," Journal of Physiology (London), Vol. 153, No. 2, 1960, pp. 331-349.

[9] V. E. Amassian and J. L. Et De Vito, "La Transmission Dans le Noyau de Burdach,” Coll. int. Cent. nat. Rech. sci., Vol. 67, No., 1957, pp. 353-393.

[10] P. Andersen, J. C. Eccles, T. Oshima and R. F. Schmidt, "Mechanisms of Synaptic Transmission in the Cuneate Nucleus,” Journal of Neurophysiology, Vol. 27, No. 6, 1964, pp. 1096-1116.

[11] S. J. Jabbur and N. R. Banna, "Widespread Cutaneous Inhibition in Dorsal Column Nuclei," Journal of Neurophysiology, Vol. 33, No. 5, 1970, pp. 616-624.

[12] M. Montes, "Camels: Evolution, Migration, and Physiology,” Accessed 2003.

http://www.marisamontes.com/all_about_camels.htm

[13] Calamunnda Camel Farm Website, Accessed 2000. http://www.camelfarm.com/camels/camels_about.html

[14] C. A. Fox, M. Ubeda-Purkiss, H. K. Ihrig and D. Biagioli, “Zinc Chromate Modification of the Golgi Technic,” Journal of Biotechnic and Histochemistry, Vol. 26, No. 2, 1951, pp. 109-114. doi:10.3109/10520295109113191

[15] V. Braitenberg, V. Guglielmotti and E. Sada, "Correlation of Crystal Growth with the Staining of Axons by the Golgi Procedure,” Journal of Biotechnic and Histochemistry, Vol. 42, No. 6, 1967, pp. 277-283. doi:10.3109/10520296709115026

[16] P. E. Bermejo, C. E. Jimenez, C. V. Torres and C. Avendano, "Quantitative Stereological Evaluation of the Gracile and Cuneate Nuclei and Their Projection Neurons in the Rat," Journal of Comparative Neurology, Vol. 463, No. 4, 2003, pp. 419-433. doi:10.1002/cne.10747

[17] K. J. Berkley, R. J. Bwdell, A. Blomqvist and Markbull, "Output Systems of the Dorsal Column Nuclei in the Cat," Brain Research Reviews, Vol. 11, No. 3, 1986, pp. 199225. doi:10.1016/0165-0173(86)90012-3

[18] S. L. Florence, J. T. Wall and J. H. Kaas, "Somatotopic Organization of Inputs from the Hand to the Spinal Gray and Cuneate Nucleus of Monkeys with Observations on the Cuneate Nucleus of Humans," Journal of Comparative Neurology, Vol. 286, No. 1, 1989, pp. 48-70. doi:10.1002/cne.902860104

[19] J. Xu and J. T. Wall, "Cutaneous Representations of the Hand and Other Body Parts in the Cuneate Nucleus of a Primate, and Some Relationships to Previously Described Cortical Representations," Somatosensory and Motor Research, Vol. 13, No. 3-4, 1996, pp. 187-197. doi:10.3109/08990229609052575

[20] S. Maslany, D. P. Crockett and M. D. Egger, "Somatotopic Organization of the Dorsal Column Nuclei in the Rat: Transganglionic Labelling with B-HRP and WGA-HRP,” Brain Research, Vol. 564, No. 1, 1991, pp. 56-65. doi:10.3109/08990229609052575 
[21] S. G. Nord, "Somatotopic Organization in the Spinal Trigeminal Nucleus, the Dorsal Column Nuclei and Related Structures in the Rat,” Journal of Comparative Neurology, Vol. 130, No. 4, 1967, pp. 343-356. doi:10.1002/cne.901300406

[22] G. F. Poggio and V. B. Mountcastle, "A Study of the Functional Contributions of the Lemniscal and Spinothalamic Systems to Somatic Sensibility," Bulletin of the Johns Hopkins Hospital, Vol. 106, 1960, pp. 266-316.

[23] J. H. Kaas and T. P. Pons, "The Somatosensory System of Primates,” In: H.D. Steklis and J. Erwin, Eds., Comparative Primate Biology, Neurosciences, Vol. 4, Alan R. Liss, Inc., New York, 1988, pp. 421-468.

[24] D. J. Tracey and P. M. E. Waite, "Somatosensory System," In: G. Paxinos, Ed., The Rat Nervous System, Academic Press, San Diego, 1995, pp. 689-704.

[25] R. L. Gulley, "Golgi Studies of the Nucleus Gracilis in the Rat," Anatomical Record, Vol. 177, No. 3, 1973, pp. 325-442. doi:10.1002/ar.1091770302

[26] H. G. J. M. Kuypers and J. D. Tuerk, "The Distribution of the Cortical Fibers within the Nuclei Cuneatus and Gracilis in the Cat,” Journal of Anatomy, Vol. 98, No. 2, 1964, pp. 143-162.

[27] P. J. Hand, "Lumbosacral Dorsal Root Terminations in the Nucleus Gracilis of the Cat. Some Observations on Terminal Degeneration in Other Medullary Sensory Nu- clei,” Journal of Comparative Neurology, Vol. 1261, No. 2, 1966, pp. 137-156. doi:10.1002/cne.901260201

[28] E. Taber, "The Cytoarchitecture of the Brain Stem of the Cat. I. Brain Stem Nuclei of Cat,” Journal of Comparative Neurology, Vol. 116, No. 1, 1961, pp. 27-70. doi:10.1002/cne.901160104

[29] P. Rakic, “Local Circuit Neurons,” MIT Press, Cambridge, 1976.

[30] A. Blomqvist and J. Westman, "Interneurons and Initial Axon Collaterals in the Feline Gracile Nucleus Demonstrated with the Rapid Golgi Technique,” Brain Research, Vol. 111, No. 2, 1976, pp. 407-410. doi:10.1002/cne.901160104

[31] L. C. Ellis and A. Rustioni, "A Correlative HRE Golgi, and EM Study of the Intrinsic Organization of the Feline Dorsal Column Nuclei,” Journal of Comparative Neurology, Vol. 197, No. 2, 1981, pp. 341-367. doi:10.1002/cne.901970210

[32] A. Rustioni and C. Sotelo, "Synaptic Organization of the Nucleus Gracilis of the Cat. Experimental Identification of Dorsal Root Fibers and Cortical Afferents,” Journal of Comparative Neurology, Vol. 155, No. 4, 1974, pp. 441468. doi:10.1002/cne.901550406

[33] Y. N. Jon and L. Y. Jan, “Dendrites (Review)," Genes and Development, Vol. 15, 2001, pp. 2627-2641. 